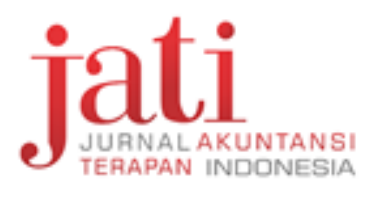

Jurnal Akuntansi Terapan Indonesia Vol 03 No 1 Hal 34-39 March 2020

\section{Analisis Sistem Informasi Akuntansi Pelayanan Pasien Badan Penyelenggara Jaminan Sosial (BPJS) Pada Badan Layanan Umum Daerah (BLUD) Rumah Sakit Umum (RSU) Jampangkulon}

Affiliation:

Universitas Muhammadiyah Sukabumi

${ }^{*}$ Correspondence:

eriansyah960@gmail.com

This Article is Avalilable in: https://journal.umy.ac.id/index. php/jati_article/view/8126

DOI:

10.18196/jati.030125

Citation:

Eriansyah, E. (2020). Analisa Sistem Informasi Akuntansi Pelayanan Pasien BPJS Pada BLUD RSU Jampangkulon. Jati: Jurnal Akuntansi Terapan Indonesia, 3(1), 34-39.

\section{Article History}

Received:

03 February 2020

Reviewed:

04 March 2020

Revised:

11 March 2020

Accepted:

31 March 2020

Topic Article:

Sector Public Accounting

\author{
Eriansyah*1 ${ }^{*}$ Chofiuddin Muchlis², Rima Purwanti ${ }^{3}$
}

\begin{abstract}
:
This study aims to find out how the analysis of accounting information system for BPJS patient service implemented at Jampangkulon Hospital. This research focuses on the BPJS patient importance of this research was carried out because of the many people who use health services in hospital with BPJS Health. Therefore researches are interested in conducting research on the analysis of accounting information system for BPJS patient service. The method used in this research is qualitative method. Data collection techniques used were interviews, observation, and documentation. Data analysis technique used in this study are by: (1) Collecting data to obtain the desired information. (2) Reducing data or summarizing the main points. (3) Present data to obtain conclusions. (4) Summarizing the results of the study. The results showed that the application of accounting informaation system in BPJS patien service at Jampangkulon Hospital has been carried out and the accounting recording system and service procedures used have been affective, because it has fulfilled all elements of the accounting information system, namely human resources, form or documents, work procedures and financial records.
\end{abstract}

Keywords: Accounting Information System, BPJS Service, Hospital's Accountancy

\begin{abstract}
Abstrak:
Tujuan dari penelitian ini adalah untuk menganalisis sistem informasi akuntansi pelayanan pasien BPJS diimplementasikan di Rumah Sakit Jampangkulon. Metode penelitian yang digunakan pada penelitian ini adalah metode kualitatif dengan melakukan observasi, wawancara, dan dokumentasi. Analisis data dilakukan dengan analisis deskriptif kualitatif. Obyek penelitian dalam penelitian ini adalah Rumah Sakit Jampangkulon. Hasil penelitian menunjukkan bahwa penerapan sistem informasi akuntansi dalam pelayanan pasien BPJS di Rumah Sakit Jampangkulon telah dilakukan dan sistem pencatatan akuntansi dan prosedur layanan yang digunakan sudah efektif, karena telah memenuhi semua elemen sistem informasi akuntansi, yaitu sumber daya manusia, formulir atau dokumen, prosedur kerja dan catatan keuangan.
\end{abstract}

Kata Kunci: Sistem Informasi Akuntansi, Layanan BPJS, Akuntansi RumahSakit 


\section{PENDAHULUAN}

Badan Penyelenggara Jaminan Sosial (BPJS) Kesehatan merupakan salah satu badan hukum milik pemerintah yang berfungsi melaksanakan program-program jaminan Kesehatan bagi masyarakat. Pengguna jaminan sosial BPJS ini pada umumnya adalah masyarakat Indonesia. Pengguna BPJS ini secara khusus terdiri dari beberapa golongan yaitu: Peserta Bantuan IUR (PBI) yang terdiri dari fakir, miskin, dan dhuafa, peserta non $\mathrm{PBI}$ yang dulunya merupakan pengguna ASKES, serta peserta mandiri. BPJS saat ini bekerjasama dengan beberapa fasilitas pelayanan Kesehatan (faskes) di seluruh Indonesia antara lain: faskes tingkat 1 (puskesmas, dokter atau bidan praktek mandiri, klinik, dan apotik) serta rumah sakit rujukan.

Mayoritas penduduk di Indonesia menggunakan jaminan Kesehatan BPJS untuk memanfaatkan fasilitas Kesehatan di Rumah Sakit. Begitu banyaknya pengguna BPJS dengan golongan yang berbeda-beda ini mengharuskan Rumah Sakit untuk memiliki system informasi akuntansi yang dapat membantu berjalannya program dan kegiatan rumah sakit secara efektif dan efisien serta dapat memberikan pelayanan prima pada pasien.

Seiring berkembangnya teknologi informasi, komputerisasi dan internet of think menjadi bagian yang tidak dapat dipisahkan dalam segala aspek kehidupan, temasuk dalam Sistem Informasi Akuntansi (SIA). Chusing dalam Hall (2001) mengartikan SIA sebagai kumpulan berbagai sumber daya modal dalam organisasi tertentu dimana sumber daya tersebut bertanggung jawab dalam menyediakan bermacam-macam informasi mulai dari informasi keuangan, informasi pengumpulan data, sampai pada informasi pengolahan data transaksi. Karena esensi dari SIA adalah berupa informasi-informasi penting yang berguna bagi semua pengguna baik pihak internal rumah sakit maupun pihak eksternal yang salah satunya adalah pengguna BPJS, maka SIA yang terkomputerisasi dengan baik menjadi perlu diterapkan sebagai wujud pertanggungjawaban rumah sakit kepada stakeholder.

Sistem informasi akuntansi juga dapat menambah nilai terhadap organisasi termasuk pada rumah sakit dengan cara mengoptimalkan pelayanan, meningkatkan efisiensi waktu pelayanan terhadap pasien, dan meningkatkan pengambilan keputusan sehingga dengan adanya sistem ini diharapkan informasi dan hasil pemeriksaan yang diberikan akurat, waktu pelayanan terhadap pasien lebih cepat, serta pengambilan keputusan jangka panjang dapat dilakukan secara lebih tepat dan terencana dengan baik.

Kontribusi penelitian ini adalah memberikan memperkaya pengetahuan mengenai akuntansi yaitu di bidang sistem informasi akuntansi bidang akuntansi, terutama mengenai praktik penerapan SIA pada pelayanan pasien BPJS di rumah sakit. Hal tersebut diharapkan dapat membantu pembuat keputusan untuk menilai bagaimana pelayanan yang diberikan kepada pasien peserta BPJS. Oleh karena itu, peneliti tertarik untuk meneliti mengenai Analisis Sistem Informasi Pelayanan Pasien BPJS di BLUD RSU Jampangkulon Kabupaten Sukabumi.

\section{METODE PENELITIAN}

Penelitian ini menggunakan metode penelitian kualitatif. Pendekatan yang dilakukan pada penelitian ini adalah pendekatan deskriptif kualitatif sesuai dengan permasalahan yang tersedia di lapangan. Penelitian ini menggunakan data primer dengan Teknik wawancara sedangkan data sekunder didapatkan dari observasi di lapangan dan dokumentasi. Bentuk wawancara yang digunakan dalam penelitian ini adalah wawancara terstruktur. Teknik menentukan sumber data terutama narasumber wawancara dilakukang dengan Teknik purposive. Obyek penelitian pada penelitian ini adalah SIA terkait proses pelayanan pasien BPJS di Rumah Sakit Umum Jampangkulon Kabupaten Sukabumi. 


\section{HASIL DAN PEMBAHASAN}

\section{Penerapan Sistem Informasi Akuntansi Pelayanan Pasien BPJS RS Jampangkulon}

Penelitian yang dilakukan di Rumah Sakit Jampangkulon terkait SIA pelayaanan pasien BPJS menemukan bahwa sejak tahun 2015 RS Jampangkulon telah menerapkan SIA untuk kasus pelayanan pasien BPJS. Sumber Daya Manusia (SDM) yang dimiliki oleh RS Jampangkulon terdiri dari tenaga kerja medis dan tenaga kerja non medis. Rumah Sakit Jampangkulon mempunyai sumber daya manusia yang terdiri dari tenaga medis dan tenaga non medis. SIA yang telah dilakukan di RS Jampangkulon sudah terkomputerisasi, dimana terdapat formulir khusus serta prosedur-prosedur tertentu untuk mendukunh kegiatan operasionalnya. Aktivitas yang umum dilaksanakan di RS Jampingkulon adalah tercantum dalam tabel 1.

Tabel 1. Aktivitas SIA Pelayanan Pasien BPJS RS Jampangkulon

\begin{tabular}{|c|c|}
\hline Unit & Aktivitas \\
\hline Unit Loby Pendaftaran & $\begin{array}{l}\text { 1. Input data pasien ke Sistem Informasi Manajemen Rumah Sakit (SIMRS) } \\
\text { dan Jaminan Kesehatan Nasional (JKN) berupa NIP, nama, no. rekam } \\
\text { medik, kode BPJS pasien, layanan yang diinginkan, dokter yg diharapkan } \\
\text { memeriksa pasien. } \\
\text { 2. Setelah proses input selesai, Formulir Jaminan Kesehatan (FJK) dan Surat } \\
\text { Elegibilitas Peserta (SEP) dicetak } 2 \text { lembar yaitu satu lembar diberikan } \\
\text { pada pasien dan satu lembar selanjutnya diarsipkan di unit layanan sebagai } \\
\text { syarat kelengkapan data. FJK selanjutnya distempel. } \\
\text { 3. Membuat lampiran tambahan untuk FJK berupa fotocopy kartu BPJS dan } \\
\text { Surat rujukan yang merupakan syarat penagihan. }\end{array}$ \\
\hline Unit Layanan & $\begin{array}{l}\text { 1. Setelah pasien selesai diperiksa, perawat kemudian mengentri Tindakan, } \\
\text { diagnosis, atau terapi yang telah dilakukan ke SIMRS, mencatatnya pada } \\
\text { buku rekam medis pasien, dan ke SEP. } \\
\text { 2. Hasil entri dicetak dan disetor kepada unit collecting. Cetakan hasil entri } \\
\text { data tersebut akan berupa rincian biaya pelayanan Kesehatan }\end{array}$ \\
\hline Unit Collecting & $\begin{array}{l}\text { 1. Setelah menerima rincian biaya dari unit layanan, unit collecting } \\
\text { mengumpulkan berkas-berkas tersebut. } \\
\text { 2. Berkas diidentifikasi dan diverifikasi kelengkapan dokumennya. } \\
\text { 3. Menyerahkan hasil verifikasi kelengkapan dokumen ke unit keuangan. }\end{array}$ \\
\hline Unit keuangan & $\begin{array}{l}\text { 1. Setelah menerima dokumen dari unit collecting, dokumen diverivikasi } \\
\text { dengan hasil entri di program Microsoft excel. } \\
\text { 2. Jika sesuai, Langkah selanjutnya adalah input data di JKN berupa nomor } \\
\text { Surat Elegibilitas Peserta (SEP), diagnosa dan Tindakan dalam pelayanan. } \\
\text { Verifikasi dilakukan } 2 \text { kali. Verifikasi pertama oleh petugas verifikator } \\
\text { rumah sakit yang dilakukan setiap hari dan verifikasi yang kedua } \\
\text { dilakukan oleh verifikator BPJS. Sebelum dilakukan verifikasi oleh } \\
\text { verifikator dari BPJS, petugas di unit verifikasi layanan kesehatan } \\
\text { membuat rekap nilai tagihan dan melaporkan nilai tagihan ke bagian } \\
\text { akuntansi rumah sakit. Setelah verifikasi selesai, maka verifikator dapat } \\
\text { melihat entri transaksi dengan } 3 \text { status klaim yaitu layak, tidak layak dan } \\
\text { pending. }\end{array}$ \\
\hline Unit Akuntansi & $\begin{array}{l}\text { 3. melakukan verifikasi dokumen dan melakukan input data-data keuangan } \\
\text { pada SIMRS. }\end{array}$ \\
\hline
\end{tabular}

\section{Prosedur Pelayanan Pasien BPJS}

Hasil wawancara yang telah dilakukan oleh peneliti dengan pihak Rumah Sakit Jampangkulon mengenai prosedur-prosedur yang diterapkan RS Jampangkulon dalam melakukan pelayanan pada pasien BPJS adalah sebagai berikut: 
a. Kepesertaan. Pasien yang akan menggunakan layanan rumah rumah sakit harus terdaftar sebagai peserta BPJS, yaitu mempunyai kartu BPJS.

b. Pasien yang daftar ke rawat jalan maupun rawat inap harus ada surat rujukan dari puskesmas, kemudian pasien mendapatkan pelayanan dari rumah sakit.

c. Untuk pasien kegawatdaruratan bisa langsung masuk ke IGD tanpa ada rujukan dari pukesmas hanya memperlihatkan kartu BPJS aktif kemudian langsung dilayani oleh pihak rumah sakit. Namun pada kenyataannya ada peserta BPJS yang klaimnya ditolak oleh BPJS dengan alasan gawat darurat. Hal ini dikarenakan kondisi gawat darurat menurut peserta bisa jadi berbeda dengan kondisi gawat darurat menurut definisi pihak BPJS.

Sedangkan Prosedur dasar Rumah Sakit secata umum meliputi:

a. Prosedur pendaftaran pasien, yaitu tahapan-tahapan saat pasien akan melakukan registrasi di rumah sakit

b. Prosedur ruang perawatan, pelayanan, dan medis, yaitu prosedur yang berjalan saat pasien sudah menerima pelayanan dari rumah sakit dengan segenap sumber daya yang dimiliki dan yang sesuai kebutuhan pasien di rumah sakit

c. Prosedur penyiapan dan penagihan klaim, yaitu prosedur yang terjadi sebagai akibat telah diselesaikannya perawatan pada pasien.

Bagian-bagian yang terlibat dalam pencatatan tarnsaksi jasa pelayanan kesehatan di Rumah Sakit Jampangkulon dalam menyusun sejumlah prosedur-prosedurnya tercantum dalam tabel 2:

Tabel 2. Prosedur Transaksi Jasa Pelalayanan Kesehatan RS Jampangkulon

\begin{tabular}{|c|c|}
\hline Penerimaan Pasien & $\begin{array}{c}\text { Menerima dan Melalukan Pencatatan } \\
\text { Data Pasien }\end{array}$ \\
\hline Rekam medis & $\begin{array}{l}\text { Melakukan pengawasan atas ketertiban pembuatan } \\
\text { catatan-catatan medis }\end{array}$ \\
\hline Akuntansi & $\begin{array}{l}\text { Menindaklanjuti laporan-laporan yang masuk dari } \\
\text { seluruh bagian rumah sakit untuk dijadikan laporan } \\
\text { keuangan yang berguna bagi puhak internal } \\
\text { (manajemen rumah sakit) maupun pihak eksternal }\end{array}$ \\
\hline Keuangan & $\begin{array}{l}\text { Mengelola penerimaan dan pengeluaran uang, } \\
\text { penanganan masalah piutang agar mencegah } \\
\text { terjadinya kerugian piutang }\end{array}$ \\
\hline
\end{tabular}

Prosedur pelayanan medis dapat dilihat dari standar operasional prosedur yang ditetapkan oleh rumah sakit untuk diterapkan di seluruh bagian Rumah Sakit. Berdasarkan hasil penelitian, secara procedural Rumah Sakit Jampangkulon telah sesuai dengan standar prosedur pelayanan yang harus dipatuhi dan dijalankan oleh bidang pelayanan keperawatan dalam pelayanan pasien. Keberadaan standar prosedur ini membuat semua tahapan menjadi rigid dan jelas, aspek dan proses penyelenggaraan pelayanan dapat sesuai dengan tindakan, sampai pada penggunaan dan bagian-bagian yang terlibat. Penyelenggaraan prosedur ini memudahkan Rumah Sakit Jampangkulon dalam upaya memberikan pelayanan yang berkualitas kepada pasien.

\section{Efektivitas Penerapan Sistem Informasi Akuntansi Pelayanan Pasien BPJS}

Kebijakan Rumah Sakit Jampangkulon Kabupaten Sukabumi yaitu dengan melaksanakan sistem informasi akuntansi pelayanan pada pasien BPJS di rumah sakit mampu mendukung pencapaian tujuan pelayanan rumah sakit. Kondisi ini dikarenakan adanya dukungan dalam upaya menciptakan sistem informasi akuntansi pada pelayanan pasien BPJS di Rumah Sakit Jampangkulon telah dilaksanakan secara efektif dan efisien dalam upaya menciptakan pelayanan yang prima kepada pasien khusunya pasien BPJS. Penerapan sistem informasi akuntansi pelayanan 
pasien BPJS di Rumah Sakit Jampangkulon dapat dikatakan cukup baik, karena setiap unsur-unsur dalam sistem tersebut seperti SDM (Sumber Daya Manusia), formulir/ dokumen, prosedur kerja dan catatan keuangan yang telah diterapkan dengan baik untuk memudahkan dalam pelaksanaan sistem informasi akuntansi yang baik, maka perusahaan akan membentuk efektivitas dalam kinerja serta hasil yang memuaskan sesuai dengan harapan manajemen.

Badan Layanan Umum Daerah (BLUD) Rumah Sakit Umum (RSU) Jampangkulon Kabupaten Sukabumi selalu berupaya untuk memaksimalkan kepuasan yaitu merupakan suatu perbandingan antara kinerja dan harapan yang dirasakan oleh seseorang pada suatu jasa ataupun produk, dengan memunculkan perasaan puas atas pelayanan yang diberikan didalam pelayanan rumah sakit tersebut. Juga merupakan salah satu upaya untuk mempertahankan keberadaan pasien khusunya pasien peserta BPJS sehingga kepuasan dapat terbentuk. Serta kepuasan merupakan suatu alat yang digunakan untuk perbaikan sistem pelayanan selanjuntnya, dimana kepuasan meruapakan suatu bentuk tolak ukur atas keberhasilan rumah sakit dalam memberikan pelayanan yang prima.

\section{KESIMPULAN}

Berdasarkan hasil penelitian yang tertuang dalam bab pembahasan, maka dapat ditarik kesimpulan akhir dari penelitian Anilisa Sistem Informasi Akuntansi Pelayanan Pasien BPJS di Badan Layanan Umum Daerah (BLUD) Rumah Sakit Umum (RSU) Jampangkulon Kabupaten Sukabumi yaitu dari hasil penelitian yang telah dilakukan bahwa sistem informasi akuntansi pelayanan pasien BPJS di Rumah Sakit Jampangkulon sudah berjalan cukup baik, hal ini ditandai oleh struktur organisasi yang memisahkan fungsi, tugas, tanggungjawab dan kewenangan masing- masing, Kelengkapan dokumen- dokumen dan bukti transaksi yang resmi, dan setiap dokumen harus diotorisasi dari fungsi lain yang terkait. Dengan demikian kemungkinan kecil terjadi penyalahgunaan dokumen- dokumen tersebut. Catatan akuntansi yang digunakan untuk mendukung sistem pelayanan kesehatan pasien BPJS berupa program Sistem Informasi Manajemen Rumah Sakit (SIM-RS) dan program Jaminan Kesehatan Nasional (JKN). Adanya bagian verifikasi atas pelayanan pasien BPJS yaitu dari bagian penagihan, administrasi dan akuntansi.

Prosedur yang digunakan Rumah Sakit Jampangkulon dapat dikatakan cukup efektif, karena bagian-bagian yang terlibat seperti bagian penerimaan pasien, rekam medis, akuntansi dan keuangan telah dijalankan secara prosedural dengan baik oleh setiap komponen yang ada di rumah sakit jampangkulon. Melalui standar prosedur yang telah diterapkan dengan jelas dikemukakan semua tahapan, aspek dan proses penyelenggaraan pelayanan berdasarkan tindakan, penyakit sampai pada penggunaan dan bagian-bagian yang terlibat.

Sedangkan efektivitas dari sistem informasi akuntansi pelayanan pasien BPJS yang ada di Rumah Sakit Jampangkulon dapat dikatakan efektif, karena sudah memenuhi unsur-unsur dari sistem informasi akuntansi yaitu SDM (Sumber Daya Manusia), formulir/ dokumen, prosedur kerja, dan catatan keuangan yang digunakan.

\section{DAFTAR PUSTAKA}

Adam, Mohtar dan Endang Siti Astuti. 2018. Efektivitas Sistem Informasi Pelayanan Pada Rumah Sakit. Vol.63. No. 1.

Bodnar, George H. William S. Hoopwood, 2000. Sistem Informasi Akuntansi. Diterjemahkan oleh Amir Abadi Jusuf dan R. M Tambun, Eidisi Keenam, Buku Satu, Salemba Empat, Jakarta.

BPJS Kesehatan. Info BPJS Kesehatan. Edisi XIV.

D. Mandola, Taliana, A. J. M. Rattu dan T. Soleman. 2015. Analisis Pengajuan Klaim BPJS Kesehatan di RSUD Dr. Sam Ratulangi Tondano. Vol. 5. No. 2 b.

Dana Ika Maria. Analisis Sistem Informasi Akuntansi Pendapatan Rawat Inap Kamar VIP RSUD Kota Lawang. Issn: 2337-56. 
Eka Wulansari Fridayanthie. 2018. Rancang Bangun Sistem Informasi Pengelolaan Data BPJS Kesehatan Karyawan Berbasis Web Pada PT Gajah Tunggal Tbk Tangerang. Vol. 6. No. 1. 2018.

Florentiana Du'a Nena. 2015. Analisa Sistem Informasi Akuntansi Dalam Mingkatkan Pengendalian Internal Atas Pendapatan Di Rumah Sakit Hermana-Lembean. Vol. 02. No. 02. Juli 2015.

James A. Hall. 2011. Accounting Information System. Seventh Edition.

Krismiaji. Sistem Informasi Akuntansi. Edisi Pertama, Januari 2002.

Marshall B. Romney, dan Paul John Steinbart. 2015. Sistem Informasi Akuntansi. Edisi 13. Salemba Empat: Jakarta.

McKeown "Management Information System : Managing with Computers".

Nugroho, Gatot Wahyu, DKK. 2018. Panduan Penulisan Skripsi Program Studi Akuntansi Universitas Muhammadiyah Sukabumi. Tanggerang Selatan: Citra Buku Media.

Nurbatin, Defia dan Pudji Lestari. 2018. Pengembangan Model Sistem Informasi Akuntansi Rumah Sakit Sebagai Informasi Pendapatan Atas Pelayanan Pasien Peserta BPJS di RSU Universitas Muhammadiyah Malang. September 2018.

Panduan Praktis BPJS Kesehatan. Teknis Verifikasi Klaim. 2014. Profil RSUD Jampangkulon. 2018.

Sugiyono, 2017. Metode Penelitian Kuantitatif, Kualitatif dan R\&D. Bandung: Alfabeta.

Suparman, Petrus dan Eli Febriana. 2018. Evaluasi Penerapan Sistem Informasi Akuntansi Pendapatan atas Pelayanan Kesehatan Pasien BPJS di PT Petro Graha MedikaGresik. Vol. 07. No. 01. Hal 94 109.

Widada, Trisna, Agus Pramusinto dan Lutfan Lazuardi. 2017. Peran BPJS Kesehatan dan ImplikasinyaTerhadap Ketahanan Masyarakat. Vol. 23. No. 2. Hal 199-216. 